\title{
Case Teaching of Engineering Material Course in the Academic Degree Education of Naval Architecture and Ocean Engineering
}

\author{
Huie $\mathrm{Hu}$ \\ Department of Chemistry and Materials \\ Naval University of Engineering \\ Wuhan, China \\ huhuie@163.com \\ Yulong $\mathrm{Hu}$ \\ Department of Chemistry and Materials \\ Naval University of Engineering \\ Wuhan, China \\ huyl1217@yahoo.cn
}

\author{
Xiaodong Kong \\ Department of Chemistry and Materials \\ Naval University of Engineering \\ Wuhan, China \\ kxd63813@hotmail.com \\ Guoming Li \\ Department of Chemistry and Materials \\ Naval University of Engineering \\ Wuhan, China \\ godmanlee@163.com
}

\begin{abstract}
Related to a wide scope of knowledge, many concepts and terminologies, the course of engineering material causes difficulties to students of engineering programming in non-materials science. Case teaching is a case-based teaching method, a heuristic teaching method, aimed to cultivate students' ability to solve actual engineering problems. In this paper, specific to cultivation objectives and engineering application background in the academic degree education of naval architecture and ocean engineering, the author has discussed the necessity and feasibility to introduce the method of case teaching in the course teaching of engineering material for the program of naval architecture and ocean engineering, and analyzed its positive role in teaching the course of engineering materials, so as to improve the overall quality of teachers and students.
\end{abstract}

Keywords-Engineering Materials; Case Teaching; Naval Architecture and Ocean Engineering; Academic Degree Education

\section{INTRODUCTION}

T Shipbuilding is an important part of the development of national economy, and the construction of ocean engineering is one of foundations to develop China's ocean development strategy. Naval architecture and ocean engineering are aimed to provide various types of equipment, design and construction of ocean engineering for water transportation, marine resources development and naval forces, is an engineering field of very important significance in the national economic development and the modernization of national defense construction.

This course is the only one for the program of naval architecture and ocean engineering focusing on an overall discussion of materials, including four parts, namely, basic knowledge and basic theories of materials science; strengthening and toughening principle, method and process

This work was supported by Education Research Project of Naval Engineering University (NUE2014224). of engineering materials; characteristics of microstructure and performance of common naval architecture and ocean engineering materials; failure analysis of naval architecture and ocean engineering components and reasonable selection of related materials [1]. It is involved in structure, performance, solidification, plastic processing, principle and process of heat treatment, application, failure analysis, material selection of metals for four commonly-used engineering materials, i.e. metals, ceramics, polymers and composites, etc. This course is involved in a mass of content, concepts, terminologies and some abstract microstructures, which are invisible and unable to touch, so students hold general opinions that it is hard to learn, to understand, to memory, and to grasp the main points, and have little interest in learning [2]. Some students only adopt the knowledgecramming method to pass this course, so their learning enthusiasm and initiative are impacted greatly [3].Such a learning mode is dramatically different from the basic idea focusing on a close combination of theoretical knowledge and practical application in teaching the course of engineering material, a dominant position of students' learning and cultivation of students' innovative thinking, problem-solving ability.

Therefore, we have conducted e beneficial exploration, put forward the application of case teaching method in the engineering material course, and have achieved good teaching effects.

\section{CharaCteristics OF CASE TEACHING METHOD}

Case teaching method is a case-based teaching method. Essentially, case is aimed to provide a dilemma in education, without a specific solution, and teachers play a role of designers and motivators in the teaching, encouraging students to actively participate in the discussion, unlike the 
traditional teaching method, in which teachers play a role of imparting knowledge $[4,5]$.

Case teaching method originated in the 1920s, advocated by Harvard Business School. At that time, a unique casebased teaching method was adopted, and those cases dated back real situation or events of business management. This method was conductive to cultivating and developing students actively participating in class discussion. After implementation, good effects were achieved. After the 1990s,

Teachers

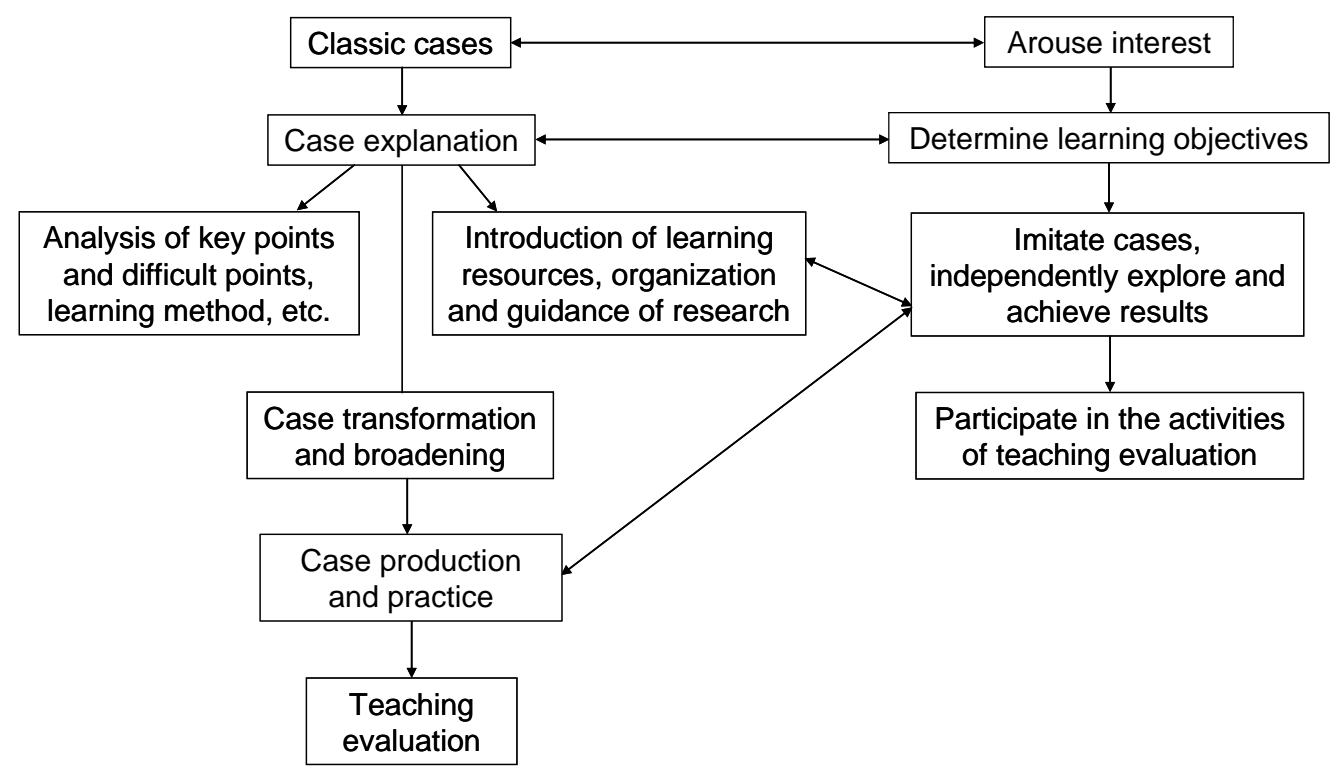

Fig. 1. Process Diagram for Implementation of Case Teaching Method

\section{Students}

Arouse interest
China's educational system began to explore the case teaching method.

Case teaching method has the following three characteristics: Encourage students to think independently, guide students to pay attention to ability instead of knowledge, and focus on two-way communication. The basic process of implementation of case teaching is shown in Fig. 1 below.

masters necessary knowledge about engineering materials, but

\section{NECESSITY OF IMPLEMENTATION OF CASE TEACHING}

In higher education, engineering courses are usually set up according to different subjects, so their contents are separated from each other. Students are lack in understanding engineering background of their learned knowledge, and some problems exist, including insufficient training corresponding to engineering practice. At the same time, most of professional books that students access to give priority to the introduction of knowledge, principles and concepts of a discipline. Therefore, in current engineering education, the problem worthy of study is how to convert knowledge into students' ability, so that students have the correct way of thinking and the way to solve the problem in the face of all kinds of engineering tasks. Introduction of case teaching method into engineering teaching is one of the good ways to overcome the above shortcomings [6-8].

Moreover, the academic degree education of naval architecture and ocean engineering is aimed to cultivate senior engineering technicians with basic skills of design, research, construction of modern naval architecture and ocean engineering, who are engaged in the departments of technology and management including naval architecture and ocean structure design, research, manufacture, inspection, use and management, etc. A senior engineering and technician adapted to the development of modern production technology not only also has the ability to deal with engineering problems. Implementation of case teaching method is to create opportunities of combining theory with practice and practical activities for students, to attain the goal of improving the comprehensive practical ability.

Thirdly, from the point of teaching effect, in the courses of engineering materials, for chapters concerning failure analysis and reasonable selection of engineering components, the case teaching method used has better teaching effect than the ordinary teaching method. When teaching chapters concerning failure analysis and reasonable selection of engineering components, teaching content is application of the learned knowledge, so the way of thinking is quite different from the previous, and students have difficulties in rapidly changing their previous learning mode in the learning process. Furthermore, students cannot grasp learning points, easy to show inattention in class. Every teacher has realized when students show inattention, if cases students are interested in are provided, they will immediately participate in learning relevant contents with an interest.

Eventually, the case teaching method can realize that teaching is learning. In the process of case teaching, teachers are not only teachers but also students. On the one hand, teachers are the leader in the process of teaching, to control the teaching progress, to guide students to consider, discuss, 
conduct research, summarize and generalize; on the other hand, through mutual discussion, teachers will not only find their weaknesses, but also learn about a large number of perceptual materials from students, helping to further improve teaching effect.

\section{CASE TEACHING EXAMPLES}

In the program of naval architecture and ocean engineering, from the perspective of its application, the course of engineering materials is aimed to expound the basic theory of engineering materials, to understand chemical composition of various materials, processing technology and the relationship between microstructure and properties, to introduce basic knowledge related to the commonly-used materials and their applications of naval architecture and ocean engineering. This course requires students to have strong professional background, and is closely linked to engineering application, so the case teaching method is used in the study of failure analysis and selection principle of hull material, etc. The content of case teaching design includes seven aspects, namely, determining case topics, assigning homework concerning cases, grouping and implementation, in-class presentations and discussions, teachers' comment and summary, students supplement and improve report, teachers' grading and feedback.

\section{A. Determining case topics.}

Cases are the starting point of case teaching, essential to implementation success of case teaching method. Before determining cases, it is required to confirm specific objectives of case teaching, make a detailed teaching plan, carefully select cases, analyze case materials, find out key problems in cases, put forward questions and recommend references. In the selection of cases, cases with professional characteristics can be selected; meanwhile, according to their own research projects, combined with current research trends and development tendency, cases related to hotspots and difficulties of disciplinary study can also be selected. In the process of learning the course of engineering materials of naval architecture and ocean engineering, taking failure analysis of $2 \mathrm{Cr} 13$ stainless steel stern shaft, which is commonly used in a certain type of naval ships, as an instance, based on the parameters of production process of stern shaft, service and background conditions, make necessary test analysis, and give full play to imagination and creativity to determine intergranular corrosion mechanism when stern shaft is at service runtime.

\section{B. Assigning homework concerning cases.}

The case teaching method was used after relevant chapters had been taught in class. At this point, students had mastered some basic concepts and methods, and collected the necessary information by reading case materials and referring to the specified data and readings, and used learned knowledge to complete case assignments. Teachers came up with relevant requirements to complete case assignments, including technical requirements and teaching arrangements, such as necessary corrosion morphological observation, microstructure analysis, composition testing, mechanical property testing, etc.; determining production and processing technology of $2 \mathrm{Cr} 13$ stainless steel stern shaft, type of corrosion products at service runtime, corrosion process, etc.

\section{Grouping and implementation.}

Every eight students were grouped, and a group leader, their respective roles and the division of work were determined. Students spent about 2 weeks in preparing it, during this period, used their spare time to independently study knowledge related to corrosion failure and consulted literature and data, fully considered and discussed it, brainstormed up, and then each group made out a case summary according to all research results of group members. Most of groups carried out macro analysis and micro analysis of corrosion morphology of stern shaft, and determined that stern shaft failure was caused by intergranular corrosion. Microscopic analysis showed that material structure, composition and properties completely conformed to the requirements of national standard, and corrosion products were distributed unevenly, having the characteristics of intergranular distribution. Through testing, main elements and corrosion products in the corrosion area were determined, focusing on iron oxide corrosion. However, analyses of corrosion mechanism of stern shaft made by most groups were not clear, and occurrence of corrosion was not associated with $2 \mathrm{Cr} 13$ stainless steel melting process and heat treatment process of stern shaft.

\section{In-class reporting and discussion.}

Two credit hours are specially used for reporting and discussion. Reporting shall be presided over by teachers, each group reports the case accomplished by using PPT. Teachers and other group members question about the content, and request members of the reporting group to reply. In the process of concentrative discussion, students play a leading role, and teachers only act as the role of organizer and host. The process of concentrative discussion is the process in which students deepen their understanding of cases. Through concentrative discussion and teachers' guidance, students confirm that component test and microstructure observation results of $2 \mathrm{Cr} 13$ stainless steel stern shaft are reasonable, so the stern shaft failure is not caused by materials and component factors. Through the analysis of microstructure, students show their understanding about the cause of stern shaft failure and intergranular corrosion mechanism to a certain extent. Heat treatment process of $2 \mathrm{Cr} 13$ stainless steel stern shaft is high temperature tempering, so there is a certain deviation between selection of tempering temperature and temperature control equipment tempering furnace, resulting in high temperature temper brittleness in the tempering process. Therefore, there is a free grain boundary precipitation zone at the grain boundary, which is the primary reason why intergranular corrosion occurs when $2 \mathrm{Cr} 13$ stainless steel stern shaft is at service runtime. In addition, in the process of smelting, the unreasonable degassing method leads to orientation distribution of inclusions in $2 \mathrm{Cr} 13$ stainless steel, which is secondary reason why intergranular corrosion occurs. 


\section{E. Teachers' comment and summary.}

After concentrative discussion, according to each student's report, teachers positively affirm students' correct report content through stimulation, summarize out necessary theoretical knowledge and basic principle, especially knowledge which should be independently mastered by students. Such knowledge is more easily accepted and mastered by students through examples. Teachers can put forward main problems in the process of discussion and relevant process mode, so that students' attention can be directed to how to reasonably make the overall plan for failure analysis. In addition, some open questions can be left to students appropriately, for example, as for the cause of failure analysis of $2 \mathrm{Cr} 13$ stainless steel stern shaft, how to improve production and processing technology of $2 \mathrm{Cr} 13$ stainless steel stern shaft. Through those questions, students can further reinforce the idea of reasonable selection of materials and proper use of materials.

\section{F. Students improve report.}

Based on class discussion and teachers' comments, students revise and improve the case report of the group, and submit the final report to teachers within the required time. Through the improvement of the written report, students have a firm grasp of related knowledge and a more profound understanding of failure analysis, and students' writing skill is exercised at the same time.

\section{G. Teachers' grading and feedback.}

According to students' group report and final case report submitted, combined with concentrative discussion, teachers carry out comprehensive grade and write comments, and feed back to students score and comments.

\section{REFERENCES}

[1] L. Hou, J. Yan, Z. M. Chen, "Teaching Reform Concerning An Introduction to Ship \& Oceanic Engineering," J. Nantong Vocational \& Technical Shipping College, Vol. 14, pp. 121-124, March 2015

[2] Y. H. Xie, W. Wang, "The Study and Exploration of Training Mode on Naval Architecture and Ocean Engineering Speciality in Local Universities," J. Zhejiang Ocean University (Natural Science), Vol. 27, pp. 457-461, Dec. 2008

[3] R.M. Felder and R. Brent, "How to Improve Teaching Quality," Quality Management Journal, Vol. 6, pp. 9-12, Feb. 1999

[4] A.E. Whimbey and J.J. Lochhead. Problem Solving and Comprehension: A Short Course in Analytical Reasoning. Franklin Institute Press, Philadelphia, 1982

[5] Thompson, B. E. Studio, "Pedagogy for Engineering Design," Int. J. Engineering Education, Vol. 18, pp. 39-49, Feb. 2002

[6] E. Graaff, A. Kolmos, "Characteristics of Problem-Based Learning," Int. J. Engineering Education, Vol. 19, pp. 657-662, May, 2003

[7] Y. H. Luo, X. Y. Wang, J. L. Xiong, J. S. Jin, Z. T. Fan, W. W. Lv, "Research and Practice on Production Practice of Excellent Engineer Plan," China Modern Educational Equipment, Vol 215, pp. 44-46, April 2015

[8] T. F. Nelson, R. Shoup, G. D. Kuh, M. J. Schwarz, "The effects of discipline on deep approaches to student learning and college outcomes," Research in Higher Education, Vol. 49, pp. 469-494, June 2008 